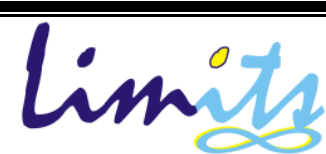

Limits: Journal of Mathematics and Its Applications

E-ISSN: 2579-8936

P-ISSN: $1829-605 \mathrm{X}$

Vol. 17, No. 2, Desember 2020, 173-180

DOI: http://dx.doi.org/10.12962/limits.v17i2.6642

\title{
Simulasi Jumlah Klaim Agregasi Berdistribusi Poisson Dengan Besar Klaim Berdistribusi Gamma dan Rayleigh
}

\author{
Rudi Ruswandi ${ }^{1}$, Aang Nuryaman ${ }^{1 *}$, Subian Saidi ${ }^{1}$ \\ ${ }^{1}$ Universitas Lampung; Jl. Soemantri Brojonegoro Bandar Lampung \\ ${ }^{1}$ Jurusan Matematika FMIPA Unila Lampung Indonesia \\ *e-mail korespondensi: aang.nuryaman@fmipa.unila.ac.id
}

Diajukan: 23 Februari 2020, Diperbaiki: 27 Mei 2020, Diterima:16 Desember 2020

\begin{abstract}
Abstrak
Klaim adalah pengalihan risiko dari tertanggung kepada penanggung. Bila klaim terjadi secara individual maka dinamakan klaim individu. Adapun koleksi beberapa klaim individu disebut klaim agregasi dalam satu periode asuransi kendaraan. Klaim agregasi terdiri dari pola jumlah (banyaknya) dan besar (nilai nominal) klaim individu. Dengan demikian model klaim agregasi dibentuk dari setiap distribusi jumlah klaim dan besar klaim. Distribusi klaim didasarkan pada fungsi kepadatan peluang dan fungsi kepadatan kumulatif. Metode konvolusi dapat digunakan untuk mendapatkan model klaim agregasi, yaitu dengan menggabungkan distribusi jumlah klaim dan besar klaim diamana nilai yang harapan yang diperoleh sebagai prediktor nilai premi murni. Dalam makalah ini, pemodelan klaim agregasi dilakukan dengan asumsi jumlah klaim dan besar klaim secara berurutan berdistribusi Poisson dan berdistribusi Gamma. Sebagai perbandingan, dibandingkan dengan besar klaim yang berdistribusi Rayleigh. Dengan menggunakan indikator VaR (value at risk) dan MSE (Mean Square Error), hasil analisis menunjukkan bahwa distribusi Rayleigh lebih baik digunakan untuk distribusi data yang memiliki nilai ekstrim.
\end{abstract}

Kata Kunci: Distribusi Gamma, Distribusi Rayleigh, Klaim Agregasi, Premi Murni, Risiko Maksimum

\section{Abstract}

A claim is a transfer of risk from the insured to the guarantor. If claims occur individually it's called individual claims. As for collections of individual claims called aggregation claims in a single period of vehicle insurance. The aggregation claims consist of a pattern of the number and amount (nominal value) of individual claims. Thus the aggregation claims model is formed from each distribution of the number and amount of claims. The distribution of claims is based on the probability density function and the cumulative density function. Convolution method can be used to obtain a claim aggregation model, which is by combining the distribution of the number of claims and the distribution of the amount of claims so that the expected value can be obtained as predictor of the pure premium value. In this paper, aggregation claim modeling be carried out with the number of claims distributed Poisson and the amount of claims distributed Gamma. As comparison, we compare it with claim amount distributed Rayleigh. By using VaR (value at risk) and MSE (Mean Square Error) indicators, the results of the analysis show that the Rayleigh distribution is better used for distributing data that has extreme values.

Keywords: Claims of Aggregation, Gamma Distribution, Rayleigh, Maximum Risk, Pure Premium 


\section{Pendahuluan}

Asuransi adalah suatu pengalihan risiko dari peserta asuransi kepada perusahaan asuransi sebagai penanggung di bawah suatu suatu kesepakatan. Dalam kesepakatan atau perjanjian ini peserta asuransi sebagai tertanggung diwajibkan membayar sejumlah uang (premi) sebagai pengganti risiko kerugian. Kemampuan mengantisipasi risiko pada periode pertanggungan berikut karakternya merupakan suatu keharusan bagi perusahaan asuransi. Tujuannya adalah untuk memperkirakan kemungkian kerugian dimasa depan. Risiko merupakan ketidakpastian suatu kejadian yang dapat mengakibatkan kerugian secara ekonomi dan dapat diistilahkan dengan klaim. Pada asuransi kendaraan bermotor, perusahaan asuransi akan memberikan manfaat (uang pertanggungan) kepada nasabah asuransi ketika terjadi klaim, sebagai konsekuensi manakala kendaraan bermotor yang diasuransikan mengalami kecelakaan. Klaim tersebut dinamakan klaim individu ketika kejadian risiko secara individual. Adapun gabungan beberapa klaim individu dinamakan klaim agregasi [1].

Klaim agregasi dan distribusi peluang klaim dapat dibentuk dari pola jumlah dan besar klaim. Distibusi peluang diskrit banyak digunakan untuk memodelkan jumlah klaim, salah satu contohnya adalah distribusi Poisson. Sebaliknya, distribusi peluang kontinu banyak digunakan untuk untuk memodelkan besar klaim. Distribusi Gamma dan Rayleigh merupakan salah satu contohnya [1]. Adapun dalam memodelkan klaim agregasi dapat menggunakan metode konvolusi. Dalam metode ini, distribusi jumlah klaim dikombinasikan dengan distribusi besar klaim untuk mendapatkan nilai harapan sebagai prediksi nilai premi murni.

Beberapa peneliti sebelumnya telah mengkaji beberapa aspek yang terkait dengan permasalahan asuransi tersebut khususnya penentuan premi. Misalnya Kartikasari [2] mengkaji bagaimana menentukan premi menggunakan model jumlah acak dengan mengkombinasikan distribusi frekuensi klaim dan distribusi severitas klaim. Kemudian Pramesti [3] membahas penentuan klaim agregasi untuk banyaknya klaim berditribusi Poisson dan besar klaim berdistribusi Rayleigh secara analitik. Selanjutnya di dalam [4], Waha dkk mengkaji penentuan premi murni dari data klaim asuransi mobil dimana banyaknya klaim berdistribusi binomial negatif dan data besarnya klaim berdistribusi log-logistik.

Pada artikel ini dikaji perbandingan besar klaim agregasi berdistribusi Gamma dan Rayleigh dengan jumlah klaim yang berdistribusi Poisson. Sebagai ilustrasi disimulasikan harga preminya berdasarkan rata-rata dan ragamnya. 


\section{Metode Penelitian}

Pada subbab ini akan dipaparkan beberapa notasi, definisi dan konsep terkait istilah yang digunakan pada artikel ini. Penjelasan lebih jauh dapat dilihat pada [1].

\subsection{Prinsip Premi Murni}

Salah satu kewajiban peserta asuransi adalah membayarkan sejumlah dana kepada perusahaan asuransi yang disebut dengan premi asuransi. Secara prinsip, premi asuransi adalah nilai manfaat (benefit) yang ingin diperoleh peserta asuransi pada jangka waktu yang telah disepakati sebelumnya. Premi murni dalam asuransi umum merupakan premi yang dibayarkan sebelum penambahan faktor loading yang dihitung berdasarkan nilai ekspektasi risiko [5].

\subsection{Konvolusi}

Terkait model risiko individu, perusahaan asuransi membuat model klaim sebagai jumlah klaim dari sejumlah individu penanggung dimana klaim individu diasumsikan saling bebas. Misalkan diketahui peubah acak $X$ dan $Y$. Misalkan pula $S=X+Y$. Ketika $X, Y$ diskrit dan non-negatif, fungsi distribusi kumulatifnya, disingkat fdk, diberikan oleh

$$
F_{S}(S)=\operatorname{Pr}(X+Y \leq s)=\sum_{Y \leq S} \operatorname{Pr}(X+Y \leq s \mid Y=y)
$$

Karena $X$ dan $Y$ saling bebas, maka $F_{S}(S)=\sum_{Y \leq S} P_{x}(s-y) p_{y}(y)$. Dengan demikian fungsi kepekatan peluang, disingkat fkp yang berkaitan dengan fungsi distribusi adalah

$$
f_{s}(S)=\frac{d}{d s} \sum P_{x}(s-y) f_{y}(y)=\sum \frac{d}{d s} P_{x}(s-y) f_{y}(y)=\sum_{Y \leq s} p_{x}(s-y) p_{y}(y)
$$

Persamaan (2) di atas disebut konvolusi dua peubah acak diskrit.

Kemudian jika $X, Y$ adalah peubah acak kontinu serta non-negatif maka fdk dan fkp dari $S$, analog dengan peubah acak diskrit, diberikan oleh

$$
\begin{aligned}
& F_{S}(S)=\int_{0}^{S} \operatorname{Pr}(X+Y \leq S \mid Y=y)=\int_{0}^{S} F_{x}(s-y) f_{y}(y) d y \\
& f_{s}(S)=\int_{0}^{S} f_{x}(s-y) f_{y}(y) d y
\end{aligned}
$$

\subsection{Klaim Agregasi}

Pada model risiko individu atau klaim individu jika unit individu $k e-i, i=1,2,3, \ldots, N$ dipandang sebagai unit besar klaim individu $k e-i$ dan dinotasikan dengan $X_{i}$ maka

$$
X=\left\{X_{i}\right\}_{i=1,2, \ldots, N}
$$

dimana peubah acak $X_{i}$ berdistribusi kontinu, identik, dan saling bebas.

Selanjutnya model klaim agregasi dikontruksi berdasarkan asumsi klaim agregasi mengikuti suatu distribusi campuran dengan klaim agregasi berupa jumlah dari $N$ klaim individu yaitu: 


$$
S=X_{1}+X_{2}+\cdots+X_{N}=\sum_{i=1}^{N} X_{i}
$$

Dengan peubah acak $N$ dan $X_{1}, i=1,2, \ldots, N$ berturut-turut merupakan frekuensi klaim dan besar klaim individu yang berdistribusi diskrit, identik dan saling bebas.

Fungsi distribusi kumulatif dari klaim agregasi:

$$
F_{S}(x)=P(S \leq x)=\sum_{i=1}^{x} P\left(\{S=x\} \cap\left\{N=n_{i}\right\}\right)
$$

Berdasarkan hukum peluang total, maka

$$
F_{S}(x)=\sum_{i=1}^{x} P\left(\{S=x\} \mid N=n_{i}\right) p\left(N=n_{i}\right)
$$

Karena $X_{1}, X_{2}, \ldots, X_{N}$ saling bebas maka berlaku

$$
P\left(\{S=x\} \mid N=n_{i}\right)=P(S=x)
$$

dengan demikian untuk suatu n klaim berlaku

$$
F_{S}(x)=\sum_{n=0}^{x} P(S=x) p(N=n)
$$

Dalam istilah konvolusi berlaku $P\left(X_{1}+X_{2}+\cdots+X_{N}=x\right)=P * P * \ldots P(x)=P^{* n}(x)$ sehingga

$$
F_{S}(x)=\sum_{n=0}^{x} P^{* n}(x) p(N=n)
$$

dengan $P^{* 0}(x)= \begin{cases}0 & , x \neq 0 \\ 1 & , x=0\end{cases}$

Fungsi kepekatan peluang klaim agregasi diperoleh dengan cara yang sama yaitu

$$
f_{S}(x)=P\left(\sum_{i=1}^{N} X_{i}\right)=\sum_{i=1}^{\infty} p\left(\{S=x\} \cap\left\{N=n_{i}\right\}\right)=\sum_{n=0}^{\infty} p^{* n}(x) p(N=n)
$$

Oleh karena itu kita punya

$$
\begin{aligned}
& E(S)=E[E(S=x \mid N=n)]=E(N) E(X) \\
& \operatorname{Var}(S)=E\left[E\left(S^{2} \mid N=n\right)\right]-(E(S))^{2}=E(N) \operatorname{Var}(X)+(E(X))^{2} \operatorname{Var}(N)
\end{aligned}
$$

\section{$2.4 \quad$ Value at Risk $(\mathrm{VaR})$}

Value at Risk (VaR) dapat dijadikan standar ukuran risiko untuk bahan evaluasi paparan risiko. Misalkan $X$ menyatakan peubah acak kerugian. Maka VaR dari $X$ pada level $100 p \%$, notasi $\operatorname{VaR}_{p}(X)$ atau $\pi_{p}$, adalah persentil $100 p$ dari distribusi $X$ yang diberikan oleh rumus sebagai berikut:

$$
\operatorname{VaR}_{p}(X)=p \times \sigma \times B
$$

dengan $p=1-\alpha$ serta $\alpha, \sigma$ dan $B$ secara berturut-turut menyatakan tingkat kepercayaan, standard devisiasi dan benefit [6]. 


\section{Hasil dan Pembahasan}

Pada simulasi yang dilakukan, klaim agregasi diasumsikan mengikuti suatu distribusi campuran yaitu jumlah klaim berdistribusi Poisson dan distribusi peluang besar klaim berdistribusi Gamma atau Rayleigh. Fungsi kepekatan peluang (fkp) dan fungsi distribusi kumulatif untuk klaim agregasi menggunakan Persamaan (5) dan (6). Dengan menggunakan asumsi tersebut, maka diperoleh $E(N)=\sum_{n=0}^{\infty} n \cdot p(n)=\lambda$ dan $\operatorname{Var}(N)=E\left(N^{2}\right)-$ $(E(N))^{2}=\lambda$. Dengan demikian untuk klaim agregasi, diperoleh

$$
E(S)=E(X) E(N) \quad \text { dan } \quad \operatorname{Var}(S)=E(N) \operatorname{Var}(X)+(E(X))^{2} \operatorname{Var}(N)
$$

Lebih jauh lagi, diasumsikan bahwa semua kendaraan yang diasuransikan berjenis sama. Pada perjanjian kontrak telah disepakati oleh perusahaan asuransi dan pemegang polis bahwa harga nilai pertanggungan adalah sebesar Rp22.0000.000,-. Nilai ini ditetapkan berdasarkan nilai-tengah harga terendah dan tertinggi dari kendaraan bermotor yang diasuransikan. Untuk menentukan besarnya nilai premi murni, dilakukan dengan simulasi data karena data real dari perusahaan asuransi tidak diperoleh. Pada penelitian ini data dibangkitan melalui kemasan program R.

Hasil simulasi data bangkitan untuk kasus jumlah klaim berdistribusi Poisson dan besar klaim berdistribusi Gamma dimana $\lambda=2, \beta=1$, dan $\alpha=2.8$, disajikan dalam Tabel 1 berikut.

Tabel 1. Data Bangkitan Jumlah Klaim berdistribusi Poisson dan Besar Klaim Berdistribusi Gamma

\begin{tabular}{clcl}
\hline $\begin{array}{c}\text { Jumlah } \\
\text { Klaim }(\mathbf{N})\end{array}$ & Besar Klaim $(\mathbf{X})$ & $\begin{array}{c}\text { Jumlah } \\
\text { Pemegang Polis }\end{array}$ & \multicolumn{1}{c}{$\begin{array}{c}\text { Rata rata besar } \\
\text { klaim/pemegang polis }\end{array}$} \\
\hline 0 & Rp0 & 12 & Rp0 \\
1 & Rp58.090.362 & 21 & Rp2.766.207 \\
2 & Rp34.118.568 & 35 & Rp974.816 \\
3 & Rp31.446.074 & 18 & Rp1.747.004 \\
4 & Rp119.885.678 & 10 & Rp11.988.567 \\
5 & Rp76.210.486 & 4 & Rp19.052.621 \\
Total & Rp319.751.168 & 100 & \\
\hline
\end{tabular}

Dengan menggunakan data bangkitan pada Tabel 1, maka diperoleh nilai harapan dari klaim agregasi secara analitik, hasil konvolusi dan simulasi seperti yang disajikan pada Tabel 2. Nilai harapan secara simulasi yang dimaksudkan adalah dengan menggunakan Toolbox yang ada di aplikasi R [7]. Sedangkan untuk nilai harapan (premi murni) dan nilai resiko yang harus ditanggung perusahaan asuransi disajikan pada Tabel 3. Nilai yang diperoleh untuk jumlah pemegang polis sebanyak 100 orang. 
Tabel 2. Nilai Harapan Klaim Agregasi Kasus Jumlah Klaim berdistribusi Poisson dan Besar Klaim Berdistribusi Gamma

\begin{tabular}{cccc}
\hline & $\mathbf{E}(\mathbf{S})$ & & $\operatorname{Var}(\mathbf{S})$ \\
\hline Hasil Analitik & Hasil Konvolusi & Berdasarkan Simulasi & \\
\hline 5.6 & 4.89037983 & 5.353567 & 13 \\
\hline
\end{tabular}

Tabel 3. Nilai Premi Murni dan Nilai Resiko Kasus Jumlah Klaim berdistribusi Poisson dan Besar Klaim Berdistribusi Gamma

\begin{tabular}{ccc}
\hline Premi Murni & $\begin{array}{c}\text { Premi Murni per } \\
\text { Pemegang Polis }\end{array}$ & $\begin{array}{c}\text { Nilai Resiko yang Ditanggung } \\
\text { Perusahaan }\end{array}$ \\
\hline Rp117.778.480 & Rp1.177.785 & Rp280.687.790 \\
\hline
\end{tabular}

Selanjutnya untuk simulasi data bangkitan dalam kasus jumlah klaim dan besar klaim secara berturut-turut berdistribusi Poisson dan Rayleigh dengan $\lambda=2=\beta$, dan $\alpha=4$, disajikan dalam Tabel 4 berikut.

Tabel 4. Data Bangkitan Jumlah Klaim berdistribusi Poisson dan Besar Klaim Berdistribusi Rayleigh

\begin{tabular}{|c|c|c|c|}
\hline $\begin{array}{c}\text { Jumlah } \\
\text { Klaim (N) }\end{array}$ & Besar Klaim (X) & $\begin{array}{c}\text { Jumlah } \\
\text { Pemegang Polis }\end{array}$ & $\begin{array}{c}\text { Rata rata besar } \\
\text { klaim/pemegang polis }\end{array}$ \\
\hline 0 & $\operatorname{Rp} 0$ & 21 & $\operatorname{Rp} 0$ \\
\hline 1 & Rp 76.184.614 & 20 & Rp 3.809.230,70 \\
\hline 2 & $\mathrm{Rp} 154.648 .406$ & 24 & $\operatorname{Rp} 6.443 .683,58$ \\
\hline 3 & $\operatorname{Rp} 61.698 .142$ & 23 & $\operatorname{Rp} 2.682 .527,91$ \\
\hline 4 & $\operatorname{Rp} 32.726 .672$ & 7 & $\operatorname{Rp} 4.675 .238,86$ \\
\hline 5 & Rp 44.573.188 & 3 & $\operatorname{Rp} 14.857 .729,33$ \\
\hline 6 & $\operatorname{Rp} 45.765 .764$ & 2 & $\operatorname{Rp} 22.882 .882 .00$ \\
\hline Total & Rp319.751.168 & 100 & \\
\hline
\end{tabular}

Dari data bangkitan di atas diperoleh nilai harapan untuk klaim agregasi berikut nilai harapan (premi murni) dan nilai resiko yang harus ditanggung perusahaan asuransi secara berurutan dapat dilihat pada Tabel 5 dan Tabel 6.

Tabel 5. Nilai Harapan Klaim Agregasi Kasus Jumlah Klaim berdistribusi Poisson dan Besar Klaim Berdistribusi Rayleigh

\begin{tabular}{cccc}
\hline \multicolumn{3}{c}{$\mathbf{E}(\mathbf{S})$} & $\operatorname{Var}$ \\
\cline { 1 - 3 } Hasil Analitik & Hasil Konvolusi & Berdasarkan Simulasi & \\
\hline $\mathbf{7 , 0 8 8 0 1 5}$ & 6,984917518 & 7.588374 & 16 \\
\hline
\end{tabular}

Tabel 6. Nilai Premi Murni dan Nilai Resiko Kasus Jumlah Klaim berdistribusi Poisson dan Besar Klaim Berdistribusi Rayleigh

\begin{tabular}{ccc}
\hline Premi Murni & $\begin{array}{c}\text { Premi Murni per } \\
\text { Pemegang Polis }\end{array}$ & $\begin{array}{c}\text { Nilai Resiko yang } \\
\text { Ditanggung Perusahaan }\end{array}$ \\
\hline $\mathrm{Rp} 166.944 .228$ & $\mathrm{Rp} 1.669 .442$ & $\mathrm{Rp} 352.000 .000$ \\
\hline
\end{tabular}

Berdasarkan hasil yang diperoleh, terlihat bahwa baik besar klaim berdistribusi Gamma maupun Rayleigh nilai harapan klaim agregasi yang diperoleh baik secara analitik [2][3], 
konvolusi maupun simulasi numerik berbeda semua. Walaupun demikian, secara statistik ketiga nilai harapan tersebut tidak berbeda secara signfikan. Pengulangan simulasi sebanyak 30 kali, ketiga nilai harapan tersebut masih berada di dalam selang antara batas bawah dan batas atas nilai harapan klaim agregasi hasil pengulangan. Batas bawah dan batas atas nilai harapan klaim agregasi untuk pengulangan 30 kali dengan besar klaim berdistribusi Gamma secara berturutturut adalah 4.741955 dan 7.743656 dengan tingkat kepercayaan 99\%. Sedangkan untuk besar klaim berdistribusi Rayleigh dengan tingkat kepercayaan yang sama batas bawahnya adalah 6.216790 dan batas atasnya adalah 8.776553 .

Untuk data bangkitan yang didasarkan pada distribusi Rayleigh, terlihat bahwa pola datanya lebih melebar jika dipandang dari distribusi Gamma. Dengan membandingkan nilai mean square error (MSE) untuk kedua distribusi diperoleh seperti yang disajikan pada Tabel 7.

Tabel 7. Perbandingan MSE

\begin{tabular}{cc}
\hline Distribusi & MSE \\
\hline Gamma & 2.603895 \\
Rayleigh & 0.3674659 \\
\hline
\end{tabular}

\section{Simpulan}

Berdasarkan paparan yang disampaikan pada bab-bab sebelumnya dapat disimpulkan bahwa distribusi Rayleigh lebih baik digunakan untuk pola sebaran data yang relatif lebih menyebar dibandingkan dengan distribusi Gamma. Keberadaan data ekstrim menjadi salah satu kunci ketika menentukan distribusi besar kalim apa yang sesuai dalam menentukan klaim agregasi.

\section{Ucapan Terima Kasih}

Penulis mengucapkan terima kasih kepada Ketua LPPM Universitas Lampung yang telah memberikan dukungan dana pada penelitian ini melalui skema Penelitian Dasar DIPA BLU Unila dengan nomor kontrak 1971/UN26.21/PN/2019.

\section{Daftar Pustaka}

[1] N. L. Bowers, H. U. Gerber, J. C. Hickman, D. A. Jones, and C. J. Nesbitt, Mathematics, 2nd ed, The Society of Actuaries, Schaumburg, Illinois. P., 1997.

[2] M.D. Kartikasari, " Premium Pricing of Liability Insurance Using Random Sum Model," Eksakta: Jurnal lImu-Ilmu IPA, 6(1), pp. 1-15, 2017 
[3] G. Pramesti, " Distribusi Rayleigh untuk Klaim Agregasi," Media Statistika, 4(2), pp. 105112,2011

[4] C.K. Waha, A.J. Rindegan and T. Manurung " Model Distribusi Data Klaim Asuransi Mobil untuk Menentukan Premi Murni," d'Cartesian: Jurnal Matematika dan Aplikasi, 8(2), pp. 108-113, 2019..

[5] R. V. Young., Encyclopedia of Actuarial Science. John Wiley \& Sons, Ltd., 2004.

[6] P. Jorion, Value At Risk, Second Edition. McGraw-Hill. New York, 2001.

[7] A. R. Effendy, “Teori Risiko Aktuaria dengan Software R,” Universitas Gajah Mada Press, Yogyakarta, 2016. 